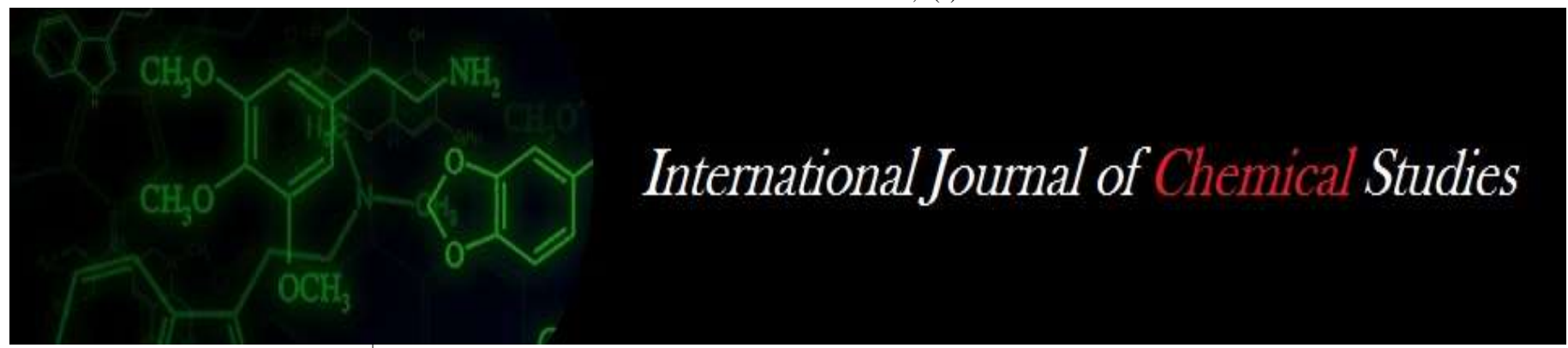

P-ISSN: 2349-8528

E-ISSN: 2321-4902

www.chemijournal.com

IJCS 2020; 8(6): 1631-1634

(C) 2020 IJCS

Received: 15-09-2020

Accepted: 25-10-2020

Alluri Sri Sai Mohan

M.Sc. Research Scholar,

Department of Horticulture,

School of agriculture, Lovely

Professional University,

Jalandhar, Punjab, India

Mahantesh Kamatyanatt

Assistant Professor, Department of Horticulture, School of agriculture, Lovely Professional University, Jalandhar, Punjab, India

\section{A review on extending storage life of kinnow}

\author{
Alluri Sri Sai Mohan and Mahantesh Kamatyanatti
}

DOI: https://doi.org/10.22271/chemi.2020.v8.i6w.10999

\begin{abstract}
Kinnow is an important crop widely cultivated in the north western part of India. Shelf life is an important part of kinnow mandarin and is possible only by using various organic, inorganic and growth regulators. Kinnow fruits are attractive because of its orange yellow colour rind and gains better market potential that helps to obtain assured income by growers. So in this current review put an effort to address the role of various waxes, packaging materials, fungicides, and plant extracts helps in an extending the storage life of kinnow. Kinnow fruits acquire greater demand in Indian markets as well as in foreign nationals.
\end{abstract}

Keywords: Kinnow, shelflife, fruit quality and waxes

\section{Introduction}

The Citrus is one of the important fruit crop belongs to Family (Rutaceae). Citrus has great diversity and distinct centres of origin. Citrus was grown in more than Hundred countries in sub-tropical, Mediterranean climate and tropical regions. Total India production of Citrus fruits comprises 12456 MT (2017-18) (Anonymous, 2018) ${ }^{[1]}$. In India citrus is grown in Andhra Pradesh, Assam, Gujarat, Haryana, Karnataka, Maharastra, Madhya Pradesh, Punjab, Rajasthan, Odisha, Uttarakhand and occupies an area of 1003 hectares. It comprises of sweet orange, grapefruit, lime, lemon and mandarins. Among them, Kinnow belong to mandarins group which is extensively cultivated in North Western regions (PB, HR) of India.

In Punjab Kinnow has emerged as important fruit crop, in-terms of production as well as area point of view. Flower of Kinnow are hermaphrodite and staminate which are borne singly in small groups in axil of leafs. Mature fruits have 9 to 12 firm segments, Fruits are medium in size and shape is globose. Sexual Propagation can be done by seeds and asexual by budding. The Kinnow harvesting starts when the fruit colour changes from green to orange. The harvesting of Kinnow fruit starts from November and continues till February whereas the demand for fruit lies in all seasons. During the peak harvesting period, due to high production farmers fetches very less price.Various factors are responsible for post-harvest losses of kinnow mandarin. The 2 major factors for limiting the storage life of fruits are physiological activities which includes ethylene production, and Respiration and second one is fungus attack (Singh and Mandal, 2006). Wax Coating can enhance the storage life of kinnow up to 45-60 days (Ahmad, et al. 2013) ${ }^{[2]}$.

\section{Role of Packaging materials in extending storage life}

Thakur, et al. (2002) ${ }^{[34]}$ indicated that fruits treated with carbendazim and packed with LDPE bags of 150-gauge thickness were found to be effective in preserving the quality of the fruit under storage. Vice versa, the overall sugar content of the fruits has continued to increase over the storage period.

Hussain, et al. (2004) ${ }^{[13]}$ had said that Maximum weight loss was seen in control fruits, minimum weight loss was seen in fruits which are in thick packaging $(0.0508 \mathrm{~mm})$ and packaging has no effect on TSS content which has increased during storage, decreasing trend in ascorbic acid from 1.59-0.63\% during storage and thick packaging proved best in enhancing shelf life of citrus fruits.

Randhawa, et al. (2009) ${ }^{[27]}$ concluded that use of edible oils like neem oils, mustard oils, coconut oils, olive oils + HDPE and wax (Citrashine wax) can extend the shelf of kinnow mandarin.
Corresponding Author: Alluri Sri Sai Mohan M.Sc. Research Scholar, Department of Horticulture, School of agriculture, Lovely Professional University, Jalandhar, Punjab, India 
Among them highest juice content and less spoilage was seen in fruits treated with neem oil+ HDP.

Mandal (2015) [20] carried out experiment on harvested kinnow fruits under ambient conditions and concluded that the maximum physiological loss in weight was observed in control, and reduced physiological loss in weight was observed in fruits treated with lac-wax and shrink wrapped.

Harjot, et al. (2016) ${ }^{[14]}$ conducted an experiment and the results showed that Compared to control fruits that retained a shelf life of 10 days, kinnow fruits are packed in PP, LDPE and HDPE films that can extend the shelf life up to 20,60 and 40 days. The use of these films helps to boost the marketability of kinnow fruit at $4-6^{\circ} \mathrm{C}$.

Baswal and Kumar (2019) ${ }^{[8]}$ said that kinnow fruits coated with edible coatings like carboxy methyl cellulose $2 \%$ and treated with different anti-sense compounds like Methyl jasmonates $(1 \mathrm{~mm})+$ perforated PP100 gauge film can enhance the shelf life of kinnow up to 60 days.

\section{Application of Waxes in extending storage life}

Ahmad, et al. (1979) ${ }^{[4]}$ conducted research and results concluded that waxing and lining materials decreased weight loss and had no impact on the physico-chemical components, while sugars / acid ratio and sugars show an growing trend, vitamin $\mathrm{C}$ and citric acid show a decreasing trend during storage.

Bayindirli, et al. (1995) ${ }^{[6]}$ said that the weight gain was 0.8 and 0.6 percent after the application of jon fresh and semper fresh coatings on mandarin. They compared various parameters such as weight loss, breathing rate, vitamin $\mathrm{C}$, TSS, and acidity during 4 weeks between coated and uncoated fruits at $20{ }^{\circ} \mathrm{C}$ and 40 percent RH. In all criteria except weight loss, both coatings were shown to be best, and jonfresh proved to be the most effective coating for weight loss reduction.

Ladaniya, et al. (2005) ${ }^{[15]}$ reported that when compared to uncoated fruit, the fruits treated with wax had good firmness, there was no substantial difference in PLW between waxed and non-waxed. It was concluded that intermittent heating as well as wax coatings would extend the shelf life of Nagpur Mandarin up to 75 days where, under normal conditions, it was only 1 week.

Bidyut, et al. (2006) ${ }^{[5]}$ had said that stayfresh treated fruits had the highest shelf life of 29 days in ambient conditions with lowest physiological loss in weight and higher vitamin $\mathrm{C}$ retention among various post harvest treatments. In addition, the fruits treated with various waxes looked attractive and also it is possible to hold the fruits without treatment (control) for 19 days under ambient conditions.

According to Sandhu, et al. (2005) ${ }^{[17]}$ fruits coated by using Citrashine wax, $\mathrm{CaCl} 22 \%$ and Bavistin (500ppm) were packed in $\mathrm{CFB}$ boxes and stored at temperature of $2-3.5^{\circ} \mathrm{C}$ and $90-95 \%$ RH and concluded that Citrashine wax coating was most effective in reducing the PLW, Firmness, and helps in improving the overall quality and appearance of the kinnow.

Babar, et al. (2007) [7] carried out investigation on physiological disorders like Chilling injury and Rind staining. And treated the fruits with Shellac wax and Polyethylene wax and concluded that fruits treated with Polyethylene wax based coatings shows less Physiological disorders like Chilling injury and Rind staining by storing fruits at $5^{\circ} \mathrm{C}$.

According to Singh, et al. (2007) [21] the treatment combination of W2C1 (Waxol $8 \%+$ captan $0.2 \%$ ) is found to be better in PLW (3.56\%), Highest total sugars (10.78\%,)
Highest TSS $(8.43 \%)$, acidity $(0.735 \%)$, highest reducing sugars $(4.84 \%)$, non-reducing sugars $(5.95 \%)$, and Vitamin C $(19.4 \mathrm{mg} / 100 \mathrm{~g})$ content.

According to Muhammad, et al. (2011) ${ }^{[16]}$ the treatment in combination with $5 \%$ Bee wax and $0.5 \%$ banlate proved to be the best treatments in term of enhancing the quality and shelf life of sweet orange fruits.

Mahajan, et al. (2013) ${ }^{[18]}$ kinnow fruits coated with Nipro fresh SS $40 \mathrm{~T}$ and SS $50^{\prime}$ followed by cold storage $\left(5-7^{\circ} \mathrm{C}, 90\right.$ $95 \% \mathrm{RH}$ for 45 days) and under environmental conditions $\left(11-19^{\circ} \mathrm{C}, 80-85 \% \mathrm{RH}\right.$ for 10 days). Were found to be successful. Because the waxes used helped in prolonging the shelf life without fruit quality degradation.

Ahmad, et al. (2013) ${ }^{[2]}$ performed experiments and analysed fruits under various storage conditions for 60 days and confirmed that In contrast to environmental conditions, (18$32^{\circ} \mathrm{C}$, RH $45-65$ percent) fruits stored at lower temperatures (4-5 ${ }^{\circ} \mathrm{C}$, RH $85-95$ percent) and ZECC had a slower rate of physio-chemical changes. And also said that the waxing with Sta-Fresh 960 of kinnow mandarin along with low temperature increases the shelf life of fruits.

Hassan, et al. (2013) performed wax coating experiments on the quality of tangerine citrus (Citrus reticulata) fruit. And said 3 separate wax emulsions $(10,12,15$ percent) are coated with fruit and processed at 2 temperature ranges $\left(5\right.$ and $\left.25^{\circ} \mathrm{C}\right)$ with 85-90 percent RH. And concluded that when compared with rest of treatments the fruits coated with $12 \%$ wax coating and $5^{\circ} \mathrm{C}$ was effective.

Mahajan, et al. (2014) ${ }^{[19]}$ studied the storage life of kinnow by using different treatments, out of the treatments Citrashine (or) terpenoidal oligoms coatings can be successfully used to enhance the shelf life at super market conditions $\left(18-20^{\circ} \mathrm{C}\right.$ and $80-85 \%$ RH) with acceptable quality for 15 days as compared to control which maintained up to 1-week storage life.

Pradeep (2016) ${ }^{[26]}$ conducted an experiment on shelf life of Kinnow Mandarin and concluded that At a temperature of 14 $-18^{\circ} \mathrm{C}$ and $45-75$ percent $\mathrm{RH}$, fruits coated with wax and mixed with Bavistin can be preserved for up to 4 weeks.

According to Sakeena, et al. (2017) ${ }^{[29]}$, during 90 days of storage, the fruits coated with PHRC wax effectively reduced the fruit decay and performed statistically at par to preserve the TSS content of fruit, sugars and acidity, antioxidant activities after storage.

Rahman, et al. (2019) [31] conducted an investigation on physico chemical changes of Khasi Mandarin fruits and results revealed that fruits treated with Bavistin, Neem leaf extract $10 \%$, and Alovera gel $0.1 \%$ were found to be the best treatment for extending the storage life.

Champa, et al. (2019) ${ }^{[9]}$ conducted research study on lime by using various Post-harvest treatments among them bio wax treatment reduces PLW and peel browning by $50 \%$ and extend the shelf life up to 60 days which was only 15 days at ambient condition and it also reduces juice $\mathrm{PH}$, Acidity.

Samita, et al. (2020) ${ }^{[30]}$ conducted research and results revealed that the fruits treated with paraffin wax@100\% had shown minimum loss in weight, minimum shrinkage was seen in fruits treated with corn starch@4\%, maximum TSS \&minimum juicy recovery was seen in control fruits, higher acidity and maximum shelf life was seen in fruits treated with Aloe vera gel @ $100 \%$.

\section{Role of Fungicides in extending storage life}

Sharma, et al. (2010) ${ }^{[32]}$ carried out experiment in Sriganganagar and revealed that Prochloraz proved most effective fungicide in reducing the post harvest fruit rotting 
and followed by carbendazium in extending the protection up to 30 and 15 days respectively. And also minimum spoilage was recorded after 60 days under cold storage conditions by using these two fungicides.

Abhay, et al. (2012) ${ }^{[3]}$ had conducted experiment on shelf life of Kazgi lime fruits. And findings showed that the edible oil emulsion coatings of coconut oil had major impact in reduction of PLW (9.67\%), TSS (8.43\%), Vitamin $\mathrm{C}(49.93 \mathrm{mg} / 100 \mathrm{ml})$ juice, fruit juice content $(42.34 \%)$. similarly, the use of this oil emulsion coating is suitable for sensory quality parameters such as look, odour, taste, external colour and no effect of mould and their growth up to 18 days. Nirmaljit, et al. (2014) ${ }^{[23]}$ carried out investigation at PAU by using post-harvest treatments on shelf life of Kinnow and stated that the fruits treated with Bavistin $500 \mathrm{ppm}$ and placed in cold storage conditions could be kept up to 45 days with higher retention of fruit quality.

Pooja, et al. (2018) ${ }^{[24]}$ carried out experiment at Hisar Agriculture university on shelf life of Kinnow Mandarin and stated that the fruits treated with Gum Arabic 10\% was the most effective coating to minimize the PLW and retained the sugar content present in fruits at all period of Storage.

According to Vivek, et al. (2018) ${ }^{[35]}$ had done research and said that Spray schedule consists of COC $(0.3 \%)$, Carbendazim $(0.1 \%)$ and $\operatorname{COC}(0.3 \%)$ and Thiophanate methyl $(0.1 \%)$ proved best among the rest of the fungicides treatments and control, Also helps in controlling the postharvest decay of fruits.

Pabitra, et al. (2019) ${ }^{[25]}$ resulted that wax $(10 \%)+$ Bavistin $(0.1 \%)$ had minimum PLW $(6.61 \%)$ And maximum recovery of juice $(43.72 \%)$ and these treatment also enhances the shelf life up to 73 days, that was on par with the rest of the treatments statistically, also maximum TSS Content was recorded in the fruits which were treated with $\mathrm{CaCl} 2(1 \%)$.

\section{Growth regulators used for enhancing shelf life}

Sharma, et al. (2011) ${ }^{[33]}$ had done study on management of post harvest diseases and results revealed that fruits dipped in KMS solution@600ppm proved much effectively than NAA @ 100 ppm in reducing the incidence of post harvest diseases expect sour rot.

Hemalatha, et al. (2015) ${ }^{[11]}$ conducted an experiment on storage life of Sweet Orange (Sathgudi) by using five treatments and various physio-chemicals parameters like PLW, Juice content, TSS, Acidity were evaluated for every 5 days intervals and found that Benzyl adenine 50PPM in addition with wax $6 \%$ is the best treatment that can increases storage life of Sathgudi for 18days. And percentage increases from $45-86 \%$.

\section{Application of Plant extracts used in extending storage life}

Rana, (2017) ${ }^{[28]}$ carried out research study in increasing shelf life of citrus by using plant extracts and concluded that cerbera odollam and capsicum frutescence at $3000 \mathrm{ppm}$ showed no fungal growth $(100 \%)$, helps in decreasing weight loss and increasing shelf life in fruits stored at room temperature compared with control fruits.

Maryam, et al. (2019) ${ }^{[22]}$ stated by using herbal extracts like garlic minimum \% weight loss, Fruit juice PH, and maximum fruit firmness, acidity, Ascorbic acid was recorded and also enhances the storage life for 30 days at room temperature of $20^{\circ} \mathrm{C}$ with $\mathrm{RH} 45-50$ percent to retain the quality parameters. Swapnil, et al. (2020) conducted research on nagpur mandarin using plant leaf extracts under cold storage conditions and reported that $20 \%$ neem leaf extract + cold storage of the fruit gives better results until the end of the storage period, followed by the coating of tulsi leaf extract.

\section{Conclusion}

After harvest kinnow being non-climacteric fruit shows no respiratory peak and less production of ethylene. There by usage of different waxes, packaging Materials, fungicides, growth regulators, plant extracts helps in extending storage life by reducing shrinkage and weight Loss. By using proper packaging materials along with suitable storage conditions the availability of kinnow fruit in the market can be extended.

\section{References}

1. Anonymous 2018, www.nhb.gov.in.

2. Ahmad MS, Thakur KS, Siddiqui MW. Post-harvest treatments for preserving quality of kinnow fruit under different storage conditions. Adv. Horti. Sci 2013;27(4):152-158.

3. Abhay B, Sailendra KP, Neha P. Effect of skin coatings on prolonging shelf life of kagzi lime fruits. Journal of food science and technology 2012;49(6):753-759.

4. Ahmad M, Khalid ZM, Farooqi WA. Effect of waxing and lining materials on storage life of some citrus fruits. Proc. Fla. State Hort. Soc 1979;92:237-240.

5. Bidyut CD, Sanjib S, Borah SC. Post-harvest management practices for shelf life extension of khasi mandarin. Indian Journal of Horticulture 2006;63(3):251255.

6. Bayindirli L, Sumnu G, Kamadan K. Effects of semperfresh and jon fresh fruit coatings on post storage quality of Satsuma Mandarins. Journal of food processing and preservation 1995;19(5):399-407.

7. Babar EB, Faqir MA. Improving storage performance of Citrus reticulata Blanco mandarin by controlling some physiological disorders. International journal of food science and technology 2007;42:495-501.

8. Baswal Arvind Kumar. Effect of postharvest treatments and packaging on storage life and quality of kinnow fruit. Journal of applied and Natural science 2019;9(2):780783.

9. Champa WAH, Gunasekara N, Wijeratnam S, Kumara BAMS. Post-harvest treatment of cinnamon Bark oil and hexanal Incorporated Biowax maintains quality and extends Markatable Life of Lime (Citrus aurantifolia Swingle). International journal of fruit science 2019, 1553-8621.

10. Deshmukh DS, Surendra RP, Rachna RR. Storage behaviour of Nagpur Mandarin Fruits as effected by Post harvest application of plant leaf extracts under cold storage condition. IJCS 2020;8(2):877-880.

11. Hemalatha V, Dilip Babu J, Siva Shankar A. Influence of growth regulators on the shelf life of Sweet Orange cv. Sathgudi. Plant Archives 2015;15(2):1101-1106.

12. Hassan ZH, Lesmayati S. Effect of wax coatings applications and storage temperatures on the quality of tangerine citrus (Citrus reticulata) var. Siam Banjar. International food research Journal 2014;21(2):641-648.

13. Hussain I, Asil M, Ahmed M, Khan M. Effect of unipackaging on the post harvest Behaviour of citrus fruits in N.W.F.P. Pakistan journal of nutrition 2004;3(6):336339.

14. Harjot SS, Pushpinder SA, Jagveer S. Effect of different packaging materials on the storage life and quality of kinnow. Res. Environ. Life. Sci 2016;9(9):1072-1075. 
15. Ladaniya MS, Shyam S, Mahalle B. Sub optimum temperature storage of Nagpur Mandarin as influenced by wax coating and intermittent warming, Indian Journal of Horticulture 2005;62(1):1-7.

16. Muhammad NS, Nadeem AA. Effect of bee wax coatings on physiochemical changes in fruits of sweet orange cV Blood Red, Sarhad J Agric 2011;27:3.

17. Mahajan BVC, Ajmer D, Sandhu KS. Effect of different post-harvest treatments on the storage life of kinnow. Journal of food science and technology 2005;42(4):296299.

18. Mahajan BVC, Dhillon WS, Mahesh Kumar. Effect of surface coatings on shelf life and quality of kinnow fruits during storage. Journal of Post-harvest technology 2013;01(01):08-15.

19. Mahajan BVC, Rupinder Singh. Influence of coatings on post-harvest physiology and shelf life of kinnow fruits under supermarket conditions. Journal of Post-harvest technology 2014;02(01):37-44.

20. Mandal G. Effect of Lac-wax, Citrashine and Individual shrink wrapping of fruits on storage life of late harvested kinnow under ambient conditions. IJBEAS 2015;1(3):8489.

21. Murlee Y, Neeraj K, Singh DB, Singh GK. Effect of post-harvest treatments on shelf life and quality of kinnow mandarin. Indian journal of horticulture 2007;67(2):243-248.

22. Maryam S, Muhammad S, Ibrar H, Nadia S, Nazia J. Influence of herbal extract and storage duration on fruit quality of china lime. Horticult Int J 2019;3(3):153-158.

23. Nirmaljit K, Anil Kumar. Impact of post-harvest treatments on shelf life of kinnow mandarin. International journal of advanced research 2014;2(5):290-295.

24. Pooja A, Suman B, Jitender K. Effect of Different Chemical treatments on Shelf Life of Kinnow Fruits. International journal of current microbiology and applied Sciences 2018;7(3):3209-3215.

25. Pabitra J, Bishnu RO, Arun K. Effect of different post harvest treatments on prolonging shelf life of Citrus reticulata Blanco. Nepalese Horticulture 2019;14:1-8.

26. Pradeep RR. Effect of postharvest treatments on quality and shelf life of mandarin. American journal of Plant Science 2016;7:1098-1105.

27. Randhawa JS, Jawandha SK, Gill PPS. Effect of highdensity polyethylene packaging with edible oil and wax coating on storage quality of kinnow mandarin. Journal of Food Technology 2009;46(2):169-171.

28. Rana Ibrahim Khaleel. Efficacy of some plant extracts and biodegradable wrapping materials as an Alternative to fungicides in increasing shelf life Citrus fruits. Open journal of ecology 2017;7:621-630.

29. Sakeena TAH, Saeed A, Ahmad SK. Comparsion of different fruit coatings to enhance the shelf life of kinnow mandarin. Pak. J Agri. Sci 2017;54(1):35-44.

30. Samita T, Saroj S, Debraj A. Effect of different post harvest treatments on prolonging shelf life and maintaining quality of sweet orange. Sustainability in food and agriculture 2020;1(2):69-75.

31. Sayed Yusuf Muzafary, Borthakur PK, Syed Wasifur Rahman. Physio- chemical changes of Khasi mandarin (Citrus reticulata Blanco) fruits as influenced by plant extracts, essential oils, and natural coatings. Internal journal of chemical studies 2019;7(2):1273-1276.

32. Sharma RN, Maharshi RP, Gaur RB. Management of post harvest spoilage of kinnow fruits by pre-harvest spraying of fungicides. Indian Phytopathology 2010;63(3):278-281.

33. Sharma RN, Maharshi RP, Gaur RB, Jeewa R. Management of post harvest diseases of kinnow fruits through plant growth regulator and food preservative. Annals of plant protection sciences 2011;19(1):122-125.

34. Thakur KS, Lal Kaushal BB, Sharma RM. Effect of different post-harvest treatments and storage conditions on the fruit quality of kinnow. Journal of food science and technology 2002;39(6):609-618.

35. Vivek B, Anil K, Goyal RK. Effect of pre-harvest application of fungicides on fruit quality of kinnow mandarin stored under ambient conditions. Int. J Pure App Biosci 2018;6(6):278-286. 